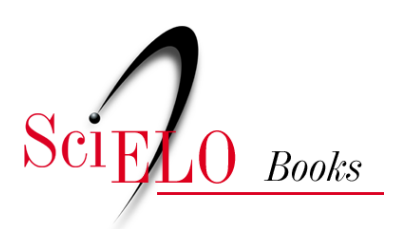

\title{
Introducción \\ Presentación de los tres casos
}

\author{
Joel M. F. Ramírez-Mendoza
}

\section{SciELO Books / SciELO Livros / SciELO Libros}

RAMÍREZ MENDONZA, J.M.F. Introducción - Presentación de los tres casos. In: Diferencias entre las reglas de exclusión probatoria colombiana e internacional penal. Análisis en tres casos de injerencias en comunicaciones privadas [online]. Bogotá: Editorial Universidad del Rosario, 2015, pp. 18-34. Opera prima collection. ISBN: 978-958-738-658-5. https://doi.org/10.7476/9789587386585.0001.

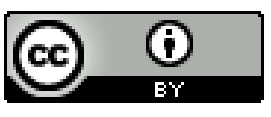

All the contents of this work, except where otherwise noted, is licensed under a Creative Commons Attribution 4.0 International license.

Todo o conteúdo deste trabalho, exceto quando houver ressalva, é publicado sob a licença Creative Commons Atribição 4.0.

Todo el contenido de esta obra, excepto donde se indique lo contrario, está bajo licencia de la licencia $\underline{\text { Creative }}$ Commons Reconocimento 4.0 . 


\section{Introducción Presentación de los tres casos}

Al estudiar la regla o cláusula de exclusión probatoria dentro del ordenamiento interno colombiano, se entiende que la regla general es la prohibición de aducir elementos de prueba que sean resultado de injerencias arbitrarias en la intimidad de las personas; por excepción, estas solamente se pueden practicar después de orden judicial, so pena de que los resultados sean excluidos del proceso. Sin embargo, encontramos que en la práctica hay casos que presentan un desarrollo diferente a lo que han venido planteando la legislación y la jurisprudencia nacional, y ello se ilustrará a través de tres casos de referencia.

En contraste, encontramos que la regla de exclusión ha tenido un tratamiento diferente a la luz del derecho internacional, principalmente en el derecho internacional humanitario, derecho internacional de los derechos humanos y el derecho internacional penal. Siendo así, la pregunta de investigación es la siguiente: ¿cuáles son las diferencias entre el derecho nacional y el derecho internacional sobre la regla de exclusión? La búsqueda de la respuesta nos impone revisar la consistencia de la posición de la Corte Constitucional cuando afirma que la regla que contiene el Estatuto 
de Roma es equiparable a la regla de exclusión nacional, según la Sentencia C-578 de 2002, que dice:

De este modo, todas las pruebas obtenidas como resultado de una violación del Estatuto o de las normas de derechos humanos internacionalmente reconocidas serán inadmisibles (regla de exclusión) cuando la violación suscite serias dudas sobre la fiabilidad de las pruebas o cuando su admisión atente "contra la integridad del juicio o redunde en grave desmedro de él". Estas disposiciones coinciden con los principios establecidos en la Constitución colombiana, que también protegen la integridad del acervo probatorio y consagran la nulidad de las pruebas obtenidas con violación del debido proceso. ${ }^{1}$

Para llegar a la respuesta, este trabajo está estructurado en tres capítulos. En el primero, señalamos el estado del arte del derecho a la intimidad dentro del derecho doméstico colombiano, junto con la excepción de que la forma legal para realizar injerencias a este derecho implica una orden judicial previa; enseguida hacemos una breve exposición del procedimiento legal vigente para adelantar la interceptación de comunicaciones por parte de la Fiscalía General de la Nación, por considerarlo necesario como marco de referencia sobre la legalidad de los procedimientos internos; luego mostramos lo regulado para las actividades de inteligencia y contrainteligencia según la Ley 1621 de 2013;

Corte Constitucional, Sentencia C-578 de 2002. 
llegamos a una explicación del concepto de la prueba ilícita y sus excepciones, y terminamos mostrando los aportes y contrastes que se presentan en los casos de ejemplo.

En el segundo capítulo buscamos una posible solución según las herramientas que nos ofrecen los instrumentos internacionales. De este modo, comenzamos exponiendo el concepto de conflicto armado, entramos a explicar los principios del derecho internacional humanitario, cómo se podrían realizar lícitamente las injerencias en las comunicaciones a la luz de esta rama del derecho internacional. Después, entramos a estudiar el derecho Internacional de los derechos humanos en relación con la regla de exclusión en casos de injerencias en las comunicaciones. Este capítulo muestra de que manera los mismos tres casos de referencia podrían ser vistos a la luz de estas dos ramas del derecho internacional.

En el tercer capítulo entramos a revisar el derecho internacional penal, en el que encontramos la regla de exclusión dentro del Estatuto de Roma, que toma como base lo que se ha venido adelantando en los tribunales ad hoc, principalmente en el Tribunal Internacional para la ex-Yugoslavia y por la Corte Europea de Derechos Humanos. Enseguida exponemos el caso concreto del desplazamiento forzado de Srebrenica y cómo las interceptaciones de comunicaciones pudieron tener importancia allí, y terminamos señalando en los tres casos de referencia cómo podrían tener un tratamiento diferente.

Tras haber expuesto estos tres capítulos, concluiremos con la precisión de las diferencias que hay entre las reglas de 
exclusión, la del derecho nacional colombiano y la postura del derecho internacional en esta materia. Adicionalmente, hacemos apertura a algunas preguntas y tareas pendientes para adelantar investigaciones y acciones futuras.

Antes de entrar a exponer los tres casos de referencia, es importante señalar que estos no son de común ocurrencia. Son esporádicos pero casi siempre envuelven gran trascendencia política, lo cual contamina de ideología el estudio jurídico y generalmente obliga a largas demoras en su decisión. ${ }^{2}$ Por esa razón, con la intención de aterrizar las ideas que se expondrán en este documento, se procuró escoger tres casos que presentan menor carga política en estos tiempos, para con ellos ilustrar más pacíficamente tres tipos de eventualidades que se presentan en este campo, primero para identificar las injerencias en comunicaciones privadas, y segundo, para dirigir la atención a aquellas que tengan una relación con el conflicto armado interno. Desafortunadamente, por la escasez de casos con estas dos características, resultó necesario incluir el del coronel (r) Plazas Vega, por hechos de 1985 que siguen siendo sensibles en la actualidad.

El primero de ellos trata de interceptaciones por la Regional de Inteligencia Militar del Ejército (RIME); el segundo caso es de captaciones incidentales que obtuvo la oficina Seccional de Inteligencia Policial (SIPOL); y el terce-

2 Por ejemplo, en el gobierno de Álvaro Uribe, hacia 2006 se presentaron interceptaciones de comunicaciones que han llevado a condenas de altos funcionarios del Estado colombiano solo en 2014, y otras varias continúan. En la campaña política de 2014 se presentaron otros casos, cuya judicialización ha seguido un tortuoso camino y aún no produce resultados en firme. 
ro, como se había señalado, son grabaciones en el espectro electromagnético por personas particulares en la toma del Palacio de Justicia.

\section{El caso de Juan Carlos Castillo por concierto para delinquir, tráfico y porte de armas de defensa personal y tráfico de armas de uso privativo de las fuerzas armadas ${ }^{3}$}

El sargento Segundo Juan Carlos Castillo, para el año 2004, traficaba armamento tanto de uso personal como de uso privativo del ejército, para grupos criminales como las autodefensas, el Frente 16 de las farc (Fuerzas Armadas Revolucionarias de Colombia) y bandas de delincuencia común, en las ciudades de Bogotá, Villavicencio, Yopal y San Vicente del Caguán. Se debe tener en cuenta que Castillo era miembro del Ejército Nacional en el Batallón Cazadores, acantonado en San Vicente del Caguán. Este proceso cuenta con otras dos personas que fueron condenadas por sentencia anticipada, y otras tres personas a quienes se les llevó a proceso penal ordinario.

Originalmente, miembros del Cuerpo Técnico de Investigación (CTI), tras autorización del fiscal delegado, hacen la interceptación de diferentes números telefónicos. Sin embargo, encuentran que algunos ya habían sido intercep-

3 Tribunal Superior del Distrito Judicial de Bogotá, Rad. 110010704002 2007-00056-01 (09-10), Sentencia del 25 de mayo de 2011. Si bien hay decisión de la Corte Suprema de Justicia-Sala de Casación Penal, Rad. 37.365, Auto de 21 de noviembre de 2011, en esta decisión no estudia de fondo el caso, sino que hace referencia a la ineptitud de la demanda que lleva a su inadmisión. 
tados por Inteligencia Militar, en concreto por la RIME 4. Así, la investigación se estaba llevando de manera conjunta entre la RIME 4 y 5 con el CTI; se demuestra que el CTI no pudo hacer algunas interceptaciones porque algunas líneas telefónicas ya estaban interceptadas por la Inteligencia Militar, y si bien el сті pudo adelantar labores con otras líneas, tuvo que redireccionar los actos de investigación por estos inconvenientes, y aun así volvió a encontrar que otras líneas también lo estaban. Aquí vemos que, principalmente la RIME 4, no desarrollaba una actividad de monitoreo, sino de interceptación de comunicaciones propiamente dicha, en cuanto hace seguimiento de números telefónicos específicos.

En este caso, las interceptaciones efectuadas por personal del CTi estuvieron conformes con la Ley 600, por lo tanto no afectó indebidamente los derechos del procesado. Ahora, si bien es cierto que el Tribunal considera que las interceptaciones del Ejército fueron ilícitas, la información obtenida sirvió para orientar la indagación en el momento de la noticia criminis. Según el Tribunal, los allanamientos y las interceptaciones realizadas propiamente por el cTI no tenían relación directa con las labores de Inteligencia Militar. Por tal razón, se consideró que había un vínculo atenuado entre las actividades de la RIME con las labores del CTI. Así, las pruebas obtenidas con orden de la Fiscalía se mantienen en el proceso, pero los informes de Inteligencia Militar son excluidos porque no tenía funciones de policía judicial.

Finalmente, a partir del análisis en conjunto del material probatorio, incluidas las interceptaciones, se consigue demostrar que el papel de Juan Carlos Castillo, en cuanto era 
una de las personas encargadas de conseguir el armamento y las piezas que se fuese a traficar, fue una persona clave para que se cometieran los tipos penales endilgados. Resaltamos que este tráfico de armamento tiene una relación con el conflicto armado vigente porque se entregaba a sujetos activos del conflicto como son las FARC o las autodefensas.

\section{El caso de la masacre de Macayepo}

El 10 de julio de 2007 la Corte Suprema de Justicia expidió auto de acusación ${ }^{4}$ contra el entonces senador Álvaro Alfonso García Romero y el representante a la Cámara Érick Julio Morris Taboada, con el Rad. 26.116, donde se judicializa: el homicidio de Georgina Narváez en San Onofre-Sucre, el 19 de noviembre de 1997; la utilización de recursos públicos para la constitución del Frente "La Mojana" de las Autodefensas Unidas de Colombia (AUC), por un contrato estatal del 4 de noviembre de 1998; y, los hechos por los que se conoce este caso, la masacre en el corregimiento de Macayepo, Carmen de Bolívar-Bolívar, el 16 de octubre de 2000 , donde se cometieron numerosos homicidios que provocaron un desplazamiento forzado masivo. Este es uno de los casos más emblemáticos de lo que se conoce como "parapolítica”.

4 Corte Suprema de Justicia-Sala de Casación Penal, Rad. 26.118, Auto de Acusación de 10 de julio de 2007. En este caso estuvo originalmente también vinculado Jairo Enrique Merlano Fernández, pero tras su renuncia a su investidura, la Corte consideró que perdió el fuero constitucional y por tanto se adelantó como un proceso ordinario. 
Con Auto del 10 de julio de 2007, se acusó a García Romero como determinador del concurso homogéneo de homicidio agravado por las víctimas de la masacre de Macayepo, por el homicidio simple de la señora Georgina Narváez, y del delito de peculado por apropiación, y autor del delito de concierto para delinquir agravado; a Morris Taboada se le acusó como autor de concierto para delinquir agravado. ${ }^{5}$ En este auto de acusación, las interceptaciones de comunicaciones sirvieron como elemento material probatorio para endilgar responsabilidad a García Romero por la masacre. La SIPOL captó incidentalmente una conversación telefónica del 7 de octubre de 2000 entre García Romero, Joaquín García Rodríguez y otro funcionario, de donde se concluye que en esta conversación se busca primero, el movimiento de infantes de marina para que recojan un gran número de vacunos que fueron robados por grupos guerrilleros; segundo, buscar el traslado del comandante de la Policía en el departamento de Sucre, Rodolfo Palomino López, porque era un obstáculo para la actuación de grupos paramilitares; y finalmente, se evidencia el desplazamiento de un grupo de paramilitares desde el golfo de Morrosquillo hasta el corregimiento de Macayepo. ${ }^{6}$

5 Es importante aclarar que hubo una ruptura de unidad procesal, por la que el representante Morris Taboada siguió con el número de original de radicado, y el caso Álvaro Alfonso García Romero terminó con la sentencia de 23 de febrero de 2010, Rad. 32.805.

6 Corte Suprema de Justicia-Sala de Casación Penal, Rad. 26.118, Auto de Acusación de 10 de julio de 2007. 
La Corte consideró que esta interceptación por la Policía Nacional era lícita porque se dio dentro del monitoreo del espectro electromagnético, obteniendo la señal de manera incidental. Este monitoreo, considera la Sala, es un procedimiento usual dentro de las actividades de inteligencia, y se hace con el fin de prevenir y contrarrestar acciones delincuenciales. Seguidamente, la Corte distingue las actividades que desarrollan los cuerpos de inteligencia, de las actividades de "interceptación de comunicaciones" que están sujetas a reserva judicial. El principal criterio diferenciador es que la actividad de inteligencia se ampara bajo el art. 218 constitucional en concordancia con el art. 75 ib., por el cual la Policía tiene "como fin primordial el mantenimiento de las condiciones necesarias para el ejercicio de los derechos y libertades públicas y para asegurar que los habitantes de Colombia vivan en paz", 7 y por tanto, le es permitido adelantar todas las actividades necesarias para prevenir la comisión de delitos, siempre y cuando se adelanten como un rastreo indeterminado y se hagan captaciones accidentales de comunicaciones. Situación diferente, según la Corte, a las actividades que desarrollan "los órganos de la jurisdicción penal y los cuerpos de policía judicial que le sirven de apoyo cuyo objeto, en cambio, se encamina a sancionar a los responsables de la ejecución de conductas punibles en particular". ${ }^{8}$ Siendo así, considera que no es reprochable la captación incidental de un diálogo privado, por un rastreo

7 Ídem.

8 Ídem. 
indeterminado que adelantaba la sipol del departamento de Sucre.

Como se sabe, la masacre de Macayepo en efecto sucedió. No se previno poniéndola en conocimiento de las autoridades judiciales, según el deber legal de denunciar la comisión de un delito que se haya conocido "por cualquier medio", 9 como ordena el art. 25 del Decreto 2700 de 1991, CPP vigente para la época de los hechos. Seguidamente, la Corte explica que si bien el informe que se presenta por la actividad de inteligencia no sirve como prueba de los hechos directamente, sí sirve como un criterio orientador de la investigación, en regla con el art. 314 de la Ley 600 (Labores previas de verificación). Dice la Corte:

Es deber de la autoridad de inteligencia en esos casos, por lo tanto, trasladar esa información sin demora a la autoridad judicial competente a través del respectivo informe, que al igual que los de Policía Judicial sólo podrá servir como criterio orientador de la investigación y en ningún caso como evidencia de la responsabilidad penal de quienes resulten implicados en virtud del producto de inteligencia. ${ }^{10}$

Haciendo las anteriores declaraciones, la Corte respondió al Ministerio Público que no hubo una vulneración del derecho a la intimidad, considerando, primero, que no hay

\footnotetext{
9 Ídem.

10 Ídem.
} 
derechos absolutos y sus límites se encuentran en los derechos de los demás; y segundo, que es un rastreo indeterminado y no interceptación de manera particular; y tercero, la Corte considera que es "absurdo despojar a las autoridades de un elemento adecuado para la lucha contra el crimen desde el punto de vista preventivo". ${ }^{11,12}$

Después, tras la ruptura de la unidad procesal, se adelantó el proceso solamente contra el representante a la Cámara Érick Julio Morris Taboada (con el mismo radicado 26.118); se dictó sentencia el 19 de diciembre de 2007, condenándosele por concierto para delinquir agravado bajo el título de autor. En este caso, se consideró en los hechos que la conversación entre el senador García Romero y Joaquín García Rodríguez hacían referencia a Morris Taboada, de donde se infiere habían hecho acuerdos ilícitos previos. ${ }^{13}$

Posteriormente la Corte Suprema de Justicia sentenció al senador Álvaro García Romero, con Rad. 32.805 del 23 de febrero de 2010, como autor de concierto para delinquir, determinador del homicidio Georgina Narváez y peculado

11 Ídem.

12 Sin embargo, la Corte después de darle contestación al Ministerio Público, dijo: “Tampoco se desecha que esa línea y todo el diálogo siguiente corresponda a una segunda llamada telefónica”. En este orden de ideas, cuando se demuestra que hay una segunda llamada interceptada se le resta credibilidad a que se haya hecho un rastreo indeterminado. Sin embargo, dijo bien la Corte que la conversación no pudo ser tan distante ni con tantas personas, como responde posteriormente a uno de los abogados defensores. Seguidamente, en la Sentencia Rad. 32.805, en la práctica probatoria no se logró desvirtuar la autenticidad de la grabación.

13 Corte Suprema de Justicia-Sala de Casación Penal, Rad. 26.118, Sentencia de 19 de diciembre de 2007. 
por apropiación, y como autor mediato en aparatos organizados de poder por la masacre de Macayepo. En este caso la defensa se enfocó en atacar la legalidad y autenticidad de las grabaciones; sin embargo, los intentos de la defensa fueron fallidos en cuanto que la Sala confirmó lo ya expuesto por el auto de acusación, y la práctica probatoria demostró que el documento era auténtico. Ahora, es importante resaltar que a pesar de que en el auto se dijo que no podría tener valor probatorio, se le trató como una prueba documental, y el testigo de acreditación termina siendo experto en esta materia para demostrar su autenticidad. Esta prueba hace que la Corte concluya lo siguiente:

En suma, encuentra la Sala que el contenido de la conversación, aunado a la información que allíse le suministró y las gestiones que le fueron encomendadas a GARCíA ROMERO, como el decurso posterior de los acontecimientos, resultan claramente indicativos de cómo el procesado no sólo organizó el grupo de autodefensas autor de la masacre, sino que además desarrolló comportamientos propios de un miembro de ese tipo de agrupaciones armadas ilegales, todo lo cual permite reprocharle a título de autor mediato los múltiples homicidios acaecidos en desarrollo de dicha incursión paramilitar ${ }^{14}$ (cursivas fuera del texto).

14 Corte Suprema de Justicia-Sala de Casación Penal, Rad. 32.805, Sentencia de 23 de febrero de 2010. 


\section{El caso del coronel Alfonso Plazas Vega y la toma al Palacio de Justicia}

Los días 6 y 7 de noviembre de 1985 se produjo lo que se conoce como la toma al Palacio de Justicia en Bogotá por el grupo subversivo M-19. En el proceso contra el coronel (r) Alfonso Plazas Vega, se lo condenó en primera instancia por la desaparición forzada de once personas. ${ }^{15}$ Después el Tribunal Superior de Bogotá, conociendo del recurso de apelación, confirma la condena pero solo por la desaparición de dos personas (la guerrillera Irma Franco Pineda y el administrador de la cafetería Carlos Augusto Rodríguez Vera). ${ }^{16}$

En este caso se presentaron las grabaciones de la interceptación de comunicaciones, que sirvieron para demostrar cómo se desarrolló la coordinación de las diferentes acciones por parte de la Brigada XIII. Las diferentes comunicaciones de los miembros de esta brigada se dieron mediante frecuencias abiertas, que fueron interceptadas por radioaficionados, ciudadanos particulares que no participaban en el combate. También se utilizaron frecuencias privadas que eran exclusivas de las fuerzas militares y de ellas no se tiene noticia. Esto se debe a que para la época se utilizaban dos tipos de

15 Las once víctimas alegadas son Carlos Augusto Rodríguez Vera, Cristina del Pilar Guarín Cortés, Bernardo Beltrán Hernández, David Suspes Celis, Gloria Stella Lizarazo Figueroa, Gloria Anzola de Lanao, Norma Constanza Esguerra, Luz Mary Portela León, Irma Franco Pineda, Héctor Jaime Beltrán Fuentes y Lucy Amparo Oviedo. Cfr., Juzgado Tercero Penal del Circuito Especializado de Bogotá, Rad. 1100113207003-2008-00025-00, Sentencia de 9 de junio de 2010.

16 Tribunal Superior del Distrito Judicial de Bogotá, Sentencia del 30 de enero de 2012, Rad. 110010704003-2008-00025-09. 
radios, unos de tipo Motorola que se podían interceptar, y otros que no, los PRC77. ${ }^{17}$

La Sala de decisión del Tribunal Superior de Bogotá considera que las grabaciones revelan cómo se enfrentaron los militares a la acción del grupo guerrillero M-19. A partir de ellas, demuestra que de manera clara e inequívoca se impartieron diferentes órdenes, entre ellas algunas ilegales, con fines de "supresión física de los rebeldes, [...] la realidad es que no les importaban los rehenes y menos los rebeldes, a quienes se referían como a los que había que 'fumigar"”. ${ }^{18}$ De igual forma, se encuentran dentro de la conversación grabada varias instrucciones que, gracias al trabajo pericial que hizo la Policía Nacional, se considera que algunas van en contra de la Constitución, de instrumentos internacionales y la Ley penal, señalando principalmente la siguiente:

ARCANO 5: R, eh... ya sabe... las instrucciones complementarias a estos son terminantes, cambio.

ARCANO 2: Ah, recibido y QSL, recibido y QSL Arcano

Cinco. 145

17 Juzgado Tercero Penal del Circuito Especializado, Sentencia del 9 de junio de 2010, Rad. 1100113207003-2008-00025-00, en el apartado referente a las comunicaciones.

18 Tribunal Superior de Bogotá, Rad. 110010704003-2008-00025-09, Sentencia del 30 de enero de 2012, en el apartado de las grabación de las comunicaciones militares. 
y un poco después:

ARCANO 5: R, está QSL ¿̇y el... el seis, uno de los seis de estos sujetos eh...?, cambio.

ARCANO 2: No, negativo, únicamente pudimos obtener inclinación sobre una sujeto, sobre una sujeto que es abogada, y que ya fue reconocida por todo el personal, cambio.

ARCANO 5: Esperamos que si está la manga no aparezca el chaleco, cambio.

ARCANO 2: Recibido, QSL. ${ }^{19}$ (cursivas fuera de texto)

Así, las grabaciones sirven como prueba para demostrar que las acciones de las fuerzas militares son ilícitas. Con esto, después el Tribunal entra a examinar la autoría mediata de la desaparición forzada, por el coronel (r) Plazas Vega, en aparatos organizados de poder.

Estas grabaciones llegaron a través de los particulares Pablo Montaña y Mike Forero Nougés, actuando como radioaficionados, quienes se las aportaron a Herbin Hoyos y Ramón Jimeno, periodistas de Radio Todelar. La Sala las considera fidedignas en cuanto se satisface la explicación de cómo se obtuvieron, la relación entre la duración del operativo y el tiempo total de las grabaciones, así como los saltos de las conversaciones, y se concluye que estas conversaciones se dieron durante el operativo. Por tanto, la Sala utiliza esta prueba documental dentro de su providencia porque fue

19 Ídem. 
aducida legalmente y contrastada con todo el acervo probatorio. Después de tratar la autenticidad de la prueba entra a analizar el derecho a la intimidad diciendo lo siguiente:

Si bien es cierto que los agentes estatales en el ejercicio de sus funciones tienen derecho a la intimidad, y con ello al secreto de las comunicaciones, de modo que no es lícito que se les intercepte cuando cumplen sus funciones constitucionales y legales, si un servidor público desborda el marco legal y utiliza medios institucionales para la comisión de delitos de lesa humanidad, y, por ejemplo, si sus conversaciones son escuchadas o grabadas por cualquier persona y éste (sic) las aporta a un proceso, las acciones del buen ciudadano no puede ser objeto de persecución penal y el documento (la grabación) podrá ser valorado probatoriamente dentro la respectiva actuación.

Esto es así porque cuando un agente estatal utiliza las herramientas que le ha entregado el Estado para el cumplimiento de sus actividades, tiene la obligación de darles un fin lícito y no podrá ampararse en que su derecho a la intimidad se vulnera cuando utiliza los medios estatales con el propósito de cometer delitos de lesa humanidad. ${ }^{20}$

Aquí encontramos un análisis donde se considera proporcional la interceptación de un ciudadano particular a una conversación de agentes estatales, siendo válido solo en cuanto las actuaciones de estos desbordan el marco legal.

20 Ídem. 
Además, considera, primero, que no es el mismo derecho de la intimidad cuando se presenta por los mandos militares dentro de una operación, que el derecho a la intimidad que alegan los particulares frente al Estado; y segundo, que las conversaciones no tienen ningún contenido de información personal, sino que tratan de órdenes militares, ni versan sobre temas de seguridad nacional, ni secretos de Estado; tercero, las conversaciones que se presentaron en los miembros de la fuerza pública no tenían la expectativa de ser privadas en cuanto podían ser escuchadas por cualquier radioaficionado, y se muestra que cuando se querían realizar comunicaciones reservadas, se hacía a través de lo que llamaban la línea 500 o "la misteriosa". Por lo anterior, considera la Sala mayoritaria que estas grabaciones de conversaciones interceptadas son lícitas.

Sin embargo, en el salvamento de voto hay un análisis por el cual se termina cuestionando la originalidad y autenticidad de las grabaciones en cuanto estas fueron editadas, dado que no hay una continuidad coherente de la grabación; tampoco se puede tener seguridad de quiénes son los sujetos que conversan, y finalmente hay divergencias entre las grabaciones y las declaraciones que las sustentan. Por otra parte, considera que estas grabaciones son ilícitas, puesto que no están acordes a lo reglamentado por el Ministerio de Comunicaciones en el Decreto 1554 del 5 de junio de 1985, como se puede ilustrar cuando le responde al señor Montaña de la siguiente manera: 
El señor Montaña se introdujo en frecuencias no autorizadas para él como radioaficionado, con el fin de conocer lo que sucedía en ese momento en el Palacio de Justicia. Ello es así, según se verifica, porque la frecuencia en la que dice pudo captar dichas comunicaciones - 155 o 156 Mhz - está dentro del rango del equipo escáner con el que realizó tal maniobra - de 138 a $164 \mathrm{Mhz}$-, pero, no dentro de la franja de frecuencias en las que legalmente podía moverse, y a las que tenía autorización legal para acceder como radioaficionado. Baste repasar el Decreto 1554 del 5 de junio de 1985 para constatar lo afirmado. ${ }^{21}$

Expuestos los tres casos de referencia, afrontamos el plan anunciado.

21 Tribunal Superior del Distrito Judicial Bogotá, Rad. 1100107040032008-00025-09. Aclaración y salvamento de voto de la Sentencia de 30 de enero de 2012. 